\title{
Electronic Surveillance for Injury Prevention Using a Physician-Operated System
}

\author{
Amir Kimia', ${ }^{1,}$, Assaf Landschaft ${ }^{3}$, Maria Jorina', Lois Lee ${ }^{1,2}$ and Al Ozonoff ${ }^{1,2}$ \\ ${ }^{1}$ Boston Children's Hospital, Boston, MA, USA; ${ }^{2 H a r v a r d ~ M e d i c a l ~ S c h o o l, ~ B o s t o n, ~ M A, ~ U S A ; ~}{ }^{3 H a r v a r d}$ Extension School, Cambridge, \\ MA, USA
}

\section{Objective}

- Describe injury-related surveillance using clinical narratives within electronic health records

- Present a user friendly, physician transferrable operated natural language processing (NLP) module, which can identify injury related events from electronic health record narratives

- Present a variety of use cases and results

\section{Introduction}

When hazardous materials or products emerge in the market, injury prevention researchers take action to promote awareness and legislation with the goal to prevent further injuries. This cannot be achieved without reliable data on trends and outcomes identifying large cohorts with the injury of interest. Lags in providing such data will delay knowledge sharing to prevent avoidable and potentially fatal injuries.

Glass tables and earth magnets are two examples of consumer products with potential for significant injuries, particularly to children. Magnet toys caused a large number of injuries with associated morbidity and mortality. For months there were no available data to support policy or prevention initiatives. Similarly, certain disease and injury mechanisms such as penetrating oral trauma are not included as structured data and cannot be collected using ICD-9/ICD-10 codes. Data on these types of injury mechanisms exist exclusively within the clinical narrative.

\section{Methods}

Central to our methodological approach is the belief that those people creating the data (i.e. physicians) are the best people to guide and direct surveillance from clinical narrative. We created a case identification software module which we named "Dr. T" (Document Reviewing Tool).

The module uses a combination of two NLP methods: Regular expressions $^{1,2}$ (RegEx) and bag of words classifier ${ }^{3}$. The module uses a RegEx wizard accessible to researchers through innovative user interface elements, to generate strings to match in the EMR text. Cases identified using RegEx do not suffer the usual shortcomings associated with ICD-9 code based systems. We use these cases to form powerful training and validation sets for a bag of words classifier. We train the classifier and assess its performance on the validation set. Finally, the classifier is applied to unclassified data, which then presents the results to the user/reviewer.

\section{Results}

Physicians of different levels and computer user skills have used the system. Training time on the module has ranged from 1-4 hours with residents, fellows, and young faculty trained within less than an hour. Administrator support (mini help-desk) ranges from 1-5 hours per project. Table 1 presents selected projects and their impact.

\section{Conclusions}

Although only used at a single center thus far, we have demonstrated feasibility of NLP based surveillance used by clinicians for injury prevention, research, and advocacy. Our findings have been well-received by the medical literature and have made an impact on pediatric safety. NLP-based modules can make surveillance applications from the narrative form available to clinicians who otherwise would not use NLP. Our methods are open source and scalable, and dissemination of this concept answers the call for timely data in the field of injury prevention.

Table 1: Publications; Time to Complete

\begin{tabular}{|c|c|}
\hline \multicolumn{2}{|c|}{ Injury Hazards } \\
\hline Magnet related injuries increase $^{4}$ & Agbo et al. 4 weeks \\
\hline Glass table injuries $^{5}$ & Kimia et al. 3 months \\
\hline Christmas ornaments injuries $^{6}$ & Kimia, et al. 9 months \\
\hline Glass thermometer injuries $^{7}$ & Aprahamian et al. 7 months \\
\hline \multicolumn{2}{|c|}{ Injury mechanism } \\
\hline Penetrating palate injury & \\
\hline
\end{tabular}

\section{Keywords}

Injury surveillance; Natural language processing; Case identification; Software; Pediatric injury prevention

\section{References}

1. Friedl JEF. Mastering regular expressions. 3rd ed. Sebastapol, CA: O'Reilly; 2006

2. Goyvaerts J, Levithan S, Safari Tech Books Online. Regular expressions cookbook. 1st ed. Beijing ; Cambridge: Oreilly; 2009

3. Hutton JJ. Pediatric biomedical informatics computer applications in pediatric research. Translational bioinformatics,. Dordrecht ; New York: Springer; 2012

4. Agbo C, Lee L, Chiang V, et al. Magnet-related injury rates in children: a single hospital experience. J Pediatr Gastroenterol Nutr. Jul 2013;57(1):14-17

5. Kimia AA, Waltzman ML, Shannon MW, et al. Glass table-related injuries in children. Pediatr Emerg Care. Mar 2009;25(3):145-149

6. Kimia A, Lee L, Shannon M, et al. Holiday ornament-related injuries in children. Pediatr Emerg Care. Dec 2009;25(12):819-822

7. Aprahamian N, Lee L, Shannon M, Hummel D, Johnston P, Kimia A. Glass thermometer injuries: it is not just about the mercury. Pediatr Emerg Care. Oct 2009;25(10):645-647

8. Hennelly K, Kimia A, Lee L, Jones D, Porter SC. Incidence of morbidity from penetrating palate trauma. Pediatrics. Dec 2010;126(6):e15781584 